41 (3) | 2012

Recomposiciones territoriales de las periferias de las metrópolis andinas

Lima (Perú), 20-21 de septiembre de 2012Leticia (Colombia), 15 de noviembre de 2012

\title{
GDRI APOCAMO «Antropología política contemporánea en la Amazonía occidental» (2012-2015)
}

Lima (Perú), 20-21 de septiembre de 2012 / Leticia (Colombia), 15 de noviembre de 2012

Jean-Pierre Chaumeil

\section{(2) OpenEdition}

\section{Journals}

Edición electrónica

URL: http://journals.openedition.org/bifea/498

DOI: $10.4000 /$ bifea. 498

ISSN: 2076-5827

Editor

Institut Français d'Études Andines

Edición impresa

Fecha de publicación: 31 diciembre 2012

Paginación: 634-636

ISSN: 0303-7495

Referencia electrónica

Jean-Pierre Chaumeil, «GDRI APOCAMO «Antropología política contemporánea en la Amazonía occidental» (2012-2015) », Bulletin de l'Institut français d'études andines [En línea], 41 (3) | 2012 ,

Publicado el 01 agosto 2013, consultado el 05 noviembre 2020. URL : http://journals.openedition.org/ bifea/498 ; DOI : https://doi.org/10.4000/bifea.498

\section{(c) (†) $\odot$}

Les contenus du Bulletin de l'Institut français d'études andines sont mis à disposition selon les termes de la licence Creative Commons Attribution - Pas d'Utilisation Commerciale - Pas de Modification 4.0 International. 


\section{GDRI APOCAMO «ANTROPOLOGÍA POLÍTICA CONTEMPORÁNEA EN LA AMAZONÍA OCCIDENTAL» (2012-2015)}

\section{Lima (Perú), 20-21 de septiembre de 2012 \\ Leticia (Colombia), 15 de noviembre de 2012}

Desde hace más de tres décadas las sociedades indígenas de la Amazonía se han convertido en sujetos muy activos - e incluso en actores de primer planoen el escenario político de los países amazónicos. Sus reivindicaciones políticas encuentran también una amplia resonancia a nivel internacional. Este fenómeno de «hacer política» $\mathrm{o}$, si se prefiere, de politización del movimiento indígena por los propios indígenas, se observa en todos los países andinos, con diferentes particularidades y características según los casos. El grupo de investigación Apocamo del IFEA — que asocia varios centros de investigación e instituciones en Francia, Perú y Colombia- tiene como objetivo estudiar, de manera comparativa, este proceso de construcción de una representatividad política indígena, tratando de mostrar las especificidades propias a cada país (con énfasis sobre Perú y Colombia) y la manera de cómo se desplazan las fronteras de la política hoy en día. Por primera vez en la historia del Perú, un indígena awajún, Eduardo Nayap Kinin, ha sido electo al Congreso para la región Amazonas.

En el marco de las actividades del GDRI, varios eventos internacionales fueron organizados durante el año 2012. Una primera reunión, que tomo la forma de un seminario-taller intitulado «Política indígena amazónica y derecho a la consulta en Perú y Colombia», tuvo lugar los días 20 y 21 de septiembre en el campus de la PUCP (Salón de Actas). Este evento, que reunió a los miembros del GDRI, profesionales y representantes indígenas invitados, colegas y estudiantes de la Facultad de Ciencias Sociales

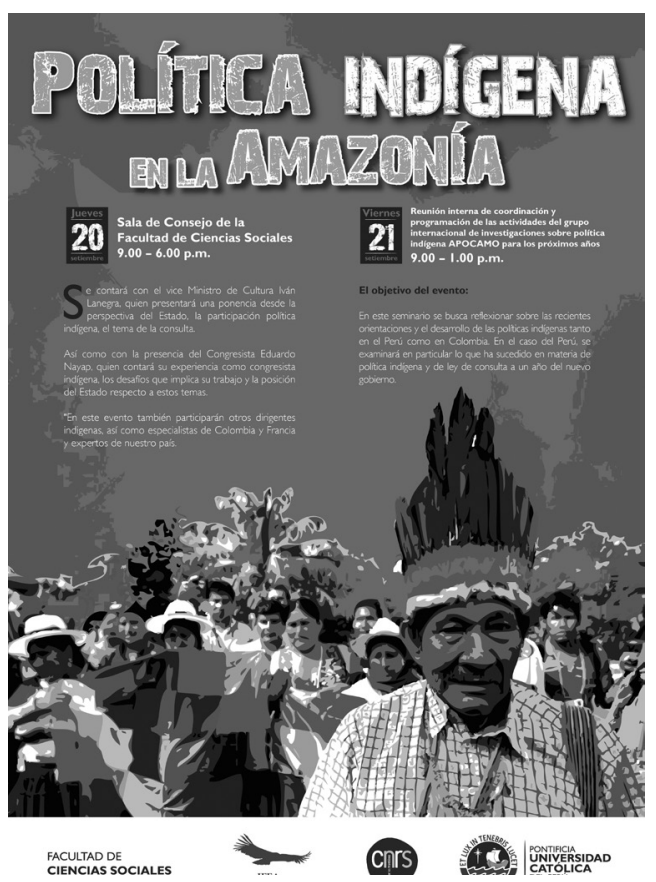


de la PUCP y de la Maestría en Estudios Amazónicos de la UNMSM, contó con la presencia del Vice-Ministro de Interculturalidad, Dr. Yvan Lanegra y de Gil Inoach, ex presidente de Aidesep, la principal organización indígena amazónica a nivel nacional. Durante el evento y referente al Perú, se examinó en particular lo que ha sucedido en materia de política indígena y de ley de consulta previa a un año del nuevo gobierno. También se enfatizó sobre el papel de la religión (especialmente adventista) en la reconfiguración de la política en zona indígena, así como sobre los procesos de captación de los líderes indígenas por parte del Estado y del sector privado (empresas petroleras y mineras). Se buscó comparar y confrontar los datos y las experiencias con lo que sucede y ha sucedido en Colombia durante estos últimos años en las políticas indígenas amazónicas.

Una segunda reunióntaller: «Transformación del liderazgo indígena frente a los cambios de política y las actividades económicas en la frontera», tuvo lugar el día 15 de noviembre en Leticia (Colombia), en las instalaciones de la Universidad Nacional de Colombia sede Amazonas/Instituto Imani, con la participación de los miembros del GDRI, profesionales y representantes indígenas invitados, colegas y estudiantes de la Maestría en Estudios Amazónicos de la Universidad Nacional

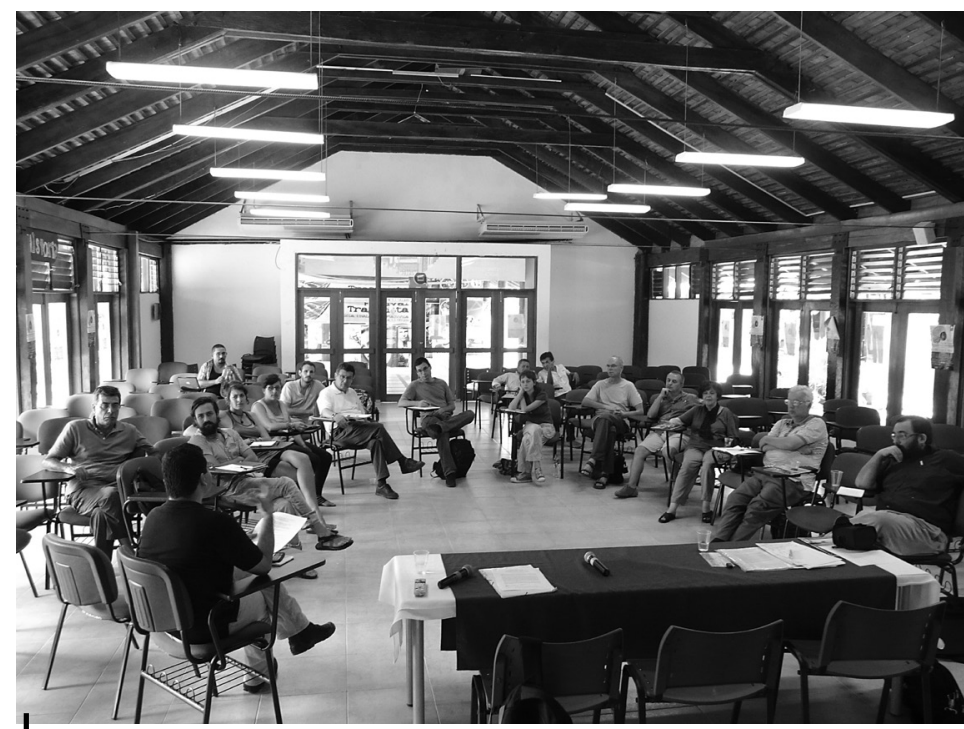

Leticia, 15 de noviembre de 2012: taller «Transformación del liderazgo indígena frente a los cambios de política y las actividades económicas en la frontera» de Colombia. Este evento benefició también de la participación del presidente del Cabildo de los pueblos indígenas del casco urbano de Leticia.

Como bien se sabe, se han incrementado los proyectos extractivos (minería, petróleo, oro y otros) y agroindustriales (soya y caña de azúcar) a gran escala, desplazando a poblaciones enteras y poniendo en peligro sus territorios. Los cambios en la política presentan un dilema para las organizaciones indígenas y sus representantes. Por una parte, hay un reconocimiento por parte de los Estados nacionales de los territorios indígenas, pero no existen los instrumentos legales para que la territorialidad indígena sea respetada por los actores económicos y políticos más poderosos. De otra parte, existe una división al interior de las comunidades indígenas en pro o en contra de la explotación a gran escala de los recursos naturales en sus territorios. Ante estas realidades, las organizaciones indígenas amazónicas deben imaginar nuevos tipos de liderazgo, incluyendo 
la implementación de formas novedosas de gobierno propio, de democracia participativa y de manejo de los recursos naturales.

Varios otros puntos fueron discutidos, referente por ejemplo a la fragmentación de las organizaciones indígenas (más de 200 para la sola Amazonía peruana), la cuestión de la burocratización y de la captación o del «reciclaje» de los antiguos lideres indígenas por parte del Estado como del sector privado, la cuestión también del reconocimiento de los cabildos urbanos indígenas en la Amazonía colombiana o de los «barrios» indígenas en los grandes ciudades en el Perú.

Para 2013, dos eventos del GDRI son programados con el objetivo de profundizar estas discusiones y reflexiones previas. La primera reunión tendrá lugar en lquitos a principios de mayo sobre la cuestión de la autonomización política indígena y los famosos «planes de vida». Este evento será organizado en colaboración con los socios colombianos de Leticia,

con la participación de los estudiantes de la Maestría de Iquitos (PUCPCETA). La segunda reunión está prevista en Quito (Ecuador) en noviembre en colaboración con la Flacso sobre las nuevas responsabilidades de la Antropología y de los antropólogos atrapados entre distintos fuegos: el Estado, la academia, las organizaciones indígenas, las ONG, las empresas extractivas, las guerrillas y el narcotráfico en las fronteras. 